\title{
Free Immunoglobulin Light Chain
}

National Cancer Institute

\section{Source}

National Cancer Institute. Free Immunoglobulin Light Chain. NCI Thesaurus. Code

C84258.

Immunoglobulin kappa and/or lambda light chains that are not bound to immunoglobulin heavy chains. These proteins are produced in vivo by B-cells but can be synthesized ex vivo for use as diagnostic or therapeutic agents. 